\title{
LEPROSY IN KOREA
}

\section{PART II}

R. G. Cochrane, M.D., F.R.C.P., D.T.M. \& H.

Adviser in Leprosy to the Ministry of Health, U.K., Technical Medical Adviser to the American Leprosy Missions, Inc.

\section{The Evolution of the Disease}

I have already referred to the necessity of studying what I have termed the pattern of the epidemic of leprosy in Korea if we are to approach the control of this disease from a practical point of view. A knowledge of the evolution of leprosy is also of great importance, if we are to devise the most economical means for its control, which, under any circumstances, will be a difficult and complex task. By the term "evolution of the disease" I mean its general development or progression in the individual case and the likelihood of a person who shows early signs of leprosy entering the infective stage or passing on to deformity and mutilation. While it is understandable from the point of view of a communicable disease that stress is placed on infectivity, yet the chances of a person being deformed is a more immediately serious consideration than the mere presence of bacilli, in so far as that person is looked upon as an economic unit. In our study of child leprosy in India we found that $7 \%$ of childhood leprosy (and we learned to recognise these lesions very early clinically) did not go on to the more serious forms but became spontaneously arrested. In Africa I have learned that while certain clinical lesions-mostly of the indeterminate macular group-may not always be seriously infective, yet the chances of ultimate deformity are very high unless adequate care is given in the form of physiotherapy and, where necessary, orthopaedic surgery. As a result of the introduction of sulphone therapy there is some danger of complacency, of assuming all is well because sulphones are being administered. In the active lepromatous case blindness may be hastened unless the eyes are carefully watched, and steps taken in time to prevent damage to the finer structures of the eye as a result of reactions. If adequate steps are not taken a person may gradually become terribly multilated, since those in charge of the case are under a false sense of security because the patient is having sulphone therapy. I suspect two things concerning leprosy in the Mongolian race: firstly, the period between the appearance of the 
first lesion and progress toward becoming an open case is relatively short; and, secondly, the proportion of true tuberculoid to other types is very low as compared with the African and Indian races. This means that of the total number of cases which progress, the majority become either lepromatous or mutilated or both of these. In order to assess the importance of leprosy and its tendency to self-healing or progression, the natural evolution of the disease in Korea should be studied.

\section{Leprosy Institutions}

It is not my intention to describe in detail my visits to colonies and leprosaria in the Southern Provinces, but to discuss in general terms the situation in respect of these as I saw them on my visits to the various institutions, and to draw attention to certain ones which I consider are of greater importance because they may have a significant role to play in the gradual development of a leprosy control system.

Taken as a whole the leprosy institutions are colonies or settlements rather than leprosaria. In my thinking a leprosarium is an institution analagous to a tuberculosis sanatorium, where the disease is treated from every aspect, including the surgical, and there is an adequate full-time medical and nursing staff. It should have a reasonably equipped laboratory for routine and special investigations and be able, if need arises, to undertake at least a limited research programme. I fear there is no such institution in Korea at present. Instead, there is the old mediaeval concept that anyone who has leprosy must be removed as far from human habitation as possible, fed, clothed, housed, treated, but with little hope of return to the community. This has resulted in banishing a a large number of patients, but the main source of infection-the early case in the house-has remained untouched. Further, as a result of this policy, the direction and organisation of leprosy institutions has fallen into the hands of the patients themselves, creating " a world within a world," peopled by persons with leprosy, who have a powerful organisation which is in a position to dictate terms to government. Patients should be enlisted in the campaign against leprosy, for their understanding co-operation is vital to its success. But when the institution is virtually in the hands of the patients, and the doctor and administrative staff act merely as intermediaries between the patients and the outside world, it is detrimental to the building up of a preventive system and harmful to the physical, mental and moral welfare of the 
patients. Sorokto Island, an extreme example of this, is a heritage from the Japanese regime. The chief medical work is done by "leprosy doctors" who, from lack of adequate qualified staff, have had only two years' theoretical training. In this connection I must pay tribute to these leprosy doctors, for they apply energy and sympathy to their task, and are learning in the hard school of experience how to cope with situations, both surgical and medical, as they find them.

\section{Specific Treatment}

I fear that as a result of sulphone treatment applied by untrained, or partially trained personnel, there is a danger of increased blindness and deformity, as reactions occur for which treatment is not supplied. In other words, sulphone therapy can aggravate eye lesions and increase blindness and hasten the development of deformity if administered without specialist knowledge. Government through KCAC (Korean Civil Assistance Command) sources supplies all special drugs, and special relief funds continue to be expended both for drugs and food. In fact I am told that 90 to Ioo per cent of all the special orphanages get food, and KCAC supplies, and in some instances 60 per cent of this is also supplied to institutions. But as outside supplies are unlikely to be continued indefinitely, every effort should be made to make institutions self-supporting as far as food is concerned.

\section{Where the Patients Live}

It is not possible to describe all the leprosy institutions in Korea, and therefore I shall select three which illustrate important points.

Ae Yang Wong, the colony on the Soonchun peninsula, was begun by Dr. Wilson many years ago. It is in a beautiful part of the country and is excellently administered. With its medical work reorganised it could develop into a first-class leprosy sanatorium linked to a comprehensive, but limited, pilot leprosy scheme under the over-all direction of the superintendent of the Chonju hospital of the American Presbyterian Mission.

Taegu, also a mission colony, was founded by Dr. A. O. Fletcher in 1919, and is superintended from the Presbyterian Hospital. As an institution it has outgrown its available space, as the town has encroached up to the gates of the hospital. It might be developed but could profitably be reduced in size.

The National Institution near Taegu (Ai Song Won) is one of the best institutions I saw. I found a spirit of independence and 
initiative which if encouraged could lead to the development in due course of a modern leprosarium. The usual weaknesses were present: lack of adequate medical supervision, irregular and uncritical supply of drugs, but the spirit of the place augurs well for the future.

In addition to the colonies and settlements there are numerous leprosy villages where patients have gathered and formed a community life of their own. There has been general support of these villages, for through them patients are receiving sulphone therapy. Unfortunately, the majority of these villages are no more than hovels on the outskirts of towns in which patients gather together and organise themselves into some kind of society for protection and companionship. More than fifty years ago Dr. Noble Mackenzie, and later Dr. Wilson, seeing the miserable plight of these people, started leprosy colonies to rescue them from living a life of mendicancy and dwelling among the graves, a people of the living dead. But the dramatic results of sulphone therapy, combined with war-time difficulties, and the migration of large populations, led leprosy patients once again to gather together and put up a few shacks, or live under bridges and make their living by begging. Seeing their sorry plight, government, with the aid of voluntary organisations, helped them to resettle in areas which, generally speaking, were poor, and supplied them with food and drugs in the hope that they would in due course recover through sulphone therapy. The reasoning seemed sound, but I fear that owing to the advancement of their disease, the irregular and intermittent supply of sulphone drugs, and the psychology of the patients, the experiment cannot be described as an unqualified success. This does not mean that all leprosy villages need to be condemned, or that there is not a place for such a scheme in the over-all plan of control.

In order that a general picture of these villages may be given I will describe from my notes two villages, one a well-run colony and the other a tragic group of pathetic people. The first village I should like to describe is that of Yong Yin (near Seoul). In I952 a group of approximately I8 patients established themselves under a bridge, and afterwards secured some land and developed under their own initiative, with the help of the KCAC team, a model village. The village, or rather colony, is on an excellent site, the houses well built, and the patients industrious; in addition to agriculture they are going in for poultry in a big way. The leader of the colony, an educated man, with a strong 
personality, works with a committee who choose the cases for admission, and as a result there are remarkably few really advanced or crippled cases. The patients themselves seem prosperous enough to buy their own supplies of sulphones, but government is supplying drugs, though intermittently. The colony itself is almost selfsupporting and has a population of 150 persons. The intention is to keep the numbers within manageable proportions, and there would have to be strict selection so that the community, owing to the admission of advanced cases, does not become pauperised because there are not sufficient able-bodied persons to maintain the economy of the village.

In contrast with this is the village of Sang Nak Won, on the outskirts of Mason, a collection of hovels on the hillside among the graves. Sulphones are being supplied irregularly and intermittently, but the pathetic reliance on sulphones is tragic and disturbing to witness. The patients eke out their miserable existence by begging, and who can blame them? Thus they add fuel to the fire of hate engendered in the well villagers' hearts for these people.

\section{Work among Children}

In every report I have read with reference to leprosy in Korea the attention of the authorities has been drawn to the large number of apparently healthy children living with infectious parents. The situation has arisen as a result of permitting marriage in leprosaria. It is unfortunate and exceedingly detrimental to the development of a sound anti-leprosy scheme to permit large numbers of apparently healthy children to live with infectious parents. The place for these children is in special observation homes not too far away from the institution, from which, after an adequate period of observation and treatment, they can be returned to relatives in their village, discharged with their parents if they are healed, or sent to one of the many homes for destitute and unwanted children which are such a tragic feature of Korea since the war.

It must be said that while there are many apparently healthy children in the leprosaria, there is some attempt to send them to preventoria. The right course is to take young children from their leprosy environment and bring them up as normal children. Unfortunately the children are separated too late, at 3 to 5 years of age, after infection has already occurred.

\section{Preventoria}

I will not describe orphanages individually. They are somewhat like leprosy villages, some well run, some poor, and many 
rather shabby and miserable. KCAC supports the orphanages entirely and there is a generous supply of food, and in many cases CARE packages. In some orphanages the children go to the ordinary school, while in others there is no such provision. In all there is a vagueness about plans for the future of the children which, to say the least, is disturbing.

Dr. Crane, of Chonju, has shown the way to deal with such a situation. He takes the babies from the Dr. Wilson Colony at birth and places them, not in a healthy children's home or preventorium, but in an "unwanted babies" ward where destitute and abandoned babies are cared for. He tells me there is no difficulty in getting these babies adopted.

The preventoria are not really preventoria in any real sense. They are what we called in India observation homes. The children have all been so grossly exposed to infection that the number of children showing signs of early leprosy is probably between 5 per cent and 30 per cent. I was rather surprised in one or two institutions to discover on superficial examination a significant number of children with very early signs of infection. Here is a rich field for research in early lesions of leprosy, and for confirming the Bombay work on contacts of open cases. Every child that is proved healthy should be brought up in an environment free from all suggestion of leprosy, and the place for such a child is in one of the numerous ordinary orphanages, not in a special one for children of leprosy patients, for by building special orphanages we just encourage the development of this "world within a world " which is so tragic. Let us not make the unwanted child's life still more tragic by perpetuating a leprosy tradition, and so guaranteeing that he will never be absorbed into society, but must for ever bear the name of "leper."

\section{Principles of Control}

I have tried to outline the present position with regard to leprosy in Korea and this, naturally, leads up to the question, "Is it possible to control the disease within a measurable time?" If we are to succeed in our ultimate objective, the control and climination of leprosy, I see no other approach except that of Public Health. I have, therefore, recommended that the first step in organising an anti-leprosy campaign throughout the land is to appoint a Public Health Officer, whose specific duty is to investigate the epidemiology of leprosy as seen in Korea, and determine what is the best method of control. This officer need not 
be a leprologist, but he should receive a preliminary briefing in leprosy to enable him to understand his task. Having selected the Public Health Officer his specific task would be to study leprosy in relation to the general principles of control in chronic infectious conditions. He would study the nature of leprosy in South Korea, and particularly investigate the contention that if the disease is controlled in the house it will be generally controlled in the country. Another task would be to ascertain the true infection rate in sanatoria, colonies and preventoria, particularly the open case rate.

While systematically visiting the field, particularly in the Provinces of Kyongsang Namdo, Kyongsang Pukto, Cholla Namdo and Cholla Pukto, he would through contacts with local authorities, missionary workers, etc., get opportunities to examine groups of people, particularly school children, and in the course of time would be able to complete the examination of a fair sample of the population, and therefore the opportunity would arise to confirm or deny the estimate that the incidence of leprosy, particularly among school children, is around IO-I2 per thousand of the population.

\section{Voluntary Organisations}

A further step in the building up of an efficient anti-leprosy system is to use voluntary organisations to prepare the way for Government to take and run the leprosy work on a country-wide basis, the control of leprosy being the inescapable duty of the National Government. In all this work there must of necessity be a close liaison with the Ministry of Health and Social Affairs and, therefore, it would be advisable to select early a national doctor, who is familiar with the English language and deeply interested in Public Health, to be a colleague of the Public Health worker appointed to study leprosy.

One of the main tasks of voluntary organisations such as the American Leprosy Missions, the Mission to Lepers, London, and the American-Korean Foundation, is to investigate, with the cooperation of KCAC, and the active approval and support of government, the possibility of setting up a pilot scheme with a view to assisting the government in formulating a comprehensive programme of leprosy control. This pilot scheme would be a demonstration to the government in one area of the principles of leprosy control, and indicate how leprosy can be integrated with the general medical programme of the country. These principles could then 
be extended gradually throughout the country and it might be possible to control leprosy within the foreseeable future.

As far as I can see there are two fields in which demonstration of the correct methods of approach can be set up. These are (I) a small but comprehensive scheme illustrating the over-all approach to the leprosy problem; (2) a demonstration of the part a general hospital can take in dealing with this problem.

\section{Pilot Project Illustrating Modern Approach to Leprosy Control}

In choosing an area for such a demonstration and ultimately a training centre, there are certain prerequisites: (a) a relatively highly endemic area; (b) the possibility of continuity over a period of years; (c) an institution which could be developed into a modern leprosy sanatorium demonstrating every aspect of relief; (d) a general hospital in the vicinity so that the leprosy work can be included in the over-all medical programme. The personnel of this institution, and especially the senior medical staff, would be willing to undertake leprosy work and co-operate in the project.

It will be well understood that under the present circumstances the group that can fulfil most nearly the above prerequisites is a group in the missionary community. There are two areas, both in provinces of relatively high endemicity, where most of these conditions can be fulfilled. One is at Soonchun with the nearby Wilson Leprosy Colony and, serving this same field, an excellent hospital under Dr. Paul Crane at Chonju. Both these institutions belong to the Presbyterian Church, and the missionaries are members of the so-called "Southern" Presbyterian Mission of America. Another institution which fulfills many of these conditions is the American Presbyterian Mission (North America), and the centre of this mission's medical activity is at Taegu. It therefore seems to me possible to visualise the leprosarium at Soonchun developing into a teaching and training centre, and the institution at Taegu being tied more closely to the hospital.

Soonchun. In order that this unit may develop adequately it would be necessary to place a doctor in charge of the leprosy colony and build a house on the outskirts of the colony in which he could settle with his family. I would not propose that a new missionary, when he is recruited, be placed in charge of the Soonchun Leprosarium at once. I have therefore suggested that if, as I believe probable, another missionary doctor is recruited for the Presbyterian Mission in this area particularly to develop 
leprosy work, he be given a briefing along similar lines to that which will be suggested for the Public Health Officer, but somewhat more inclusive and more detailed. He should be first stationed at the hospital at Chonju and share the supervision of Soonchun with the medical superintendent for six months to two years, the time depending on his aptitude for the language and his previous general medical experience. Whatever the period, he would first learn to relate leprosy to the general disease problems of the country and then be stationed as medical superintendent at a leprosarium. This step is absolutely essential if, as it should be, the determined policy is to train national doctors to undertake leprosy work.

Chongiu. The advantage of selecting Soonchun for this purpose is that at Chongju in addition to advanced surgery being undertaken there is a unit for rehabilitation of physically handicapped persons, and there is a plan for adding a physiotherapist to the staff of the hospital, who could direct this side of the work at Soonchun, teach a patient or patients to supervise the exercises necessary to prevent or relieve deformity, and teach those patients who have severe nerve dysfunction how to care for their hands and feet and how to prevent injuries and unnecessary trauma.

\section{Demonstration of the part a General Hospital can take}

A general hospital is prepared to accept for admission tuberculosis cases if temporary, emergency treatment, medical or surgical, is needed. It is also prepared to treat certain severe acute infective conditions such as typhoid, dysentery and the more chronic infective condition, syphilis; and yet, if a case of leprosy seeks temporary admission for some condition needing immediate medical or surgical care, the doctors hesitate very greatly before admitting such a case. Yet there is far less risk or danger to the other patients in the case of leprosy than of these other diseases.

Taegu. Taegu Hospital has the opportunity of setting the example in this respect and of integrating leprosy into the ordinary hospital programme. Leprosy is as much the responsibility of the department of internal medicine as tuberculosis, and the tuberculosis department might co-operate in investigating the question of leprosy in the follow-up and search for cases of tuberculosis. The opportunities in this hospital to set an example in the discovery of cases of leprosy are very great. There is also a well-trained technician in charge of the laboratory and he could develop the laboratory side of this work and train a leprosy technician to do 
the routine laboratory work and he himself develop specialist laboratory techniques-skin tissue sections, Mantoux and lepromin tests, and B.C.G. vaccination if indicated.

In addition to this short-term plan, briefly outlined, there was presented to Government a long-term plan, and the hope was expressed that such a plan would become truly indigenous-rooted in the soil-for foreign aid should only be given in order to help set up a thorough, scientific, and national Specialist Leprosy Service, covering every aspect of leprosy-prevention, treatment, education, social welfare, child care, vocational training and rehabilitation. Once this Service is established there will be great hopes that leprosy as a serious endemic disease will be brought under control.

I came away from Korea convinced of the sincerity of all voluntary organisations, and of Government, in their efforts to combat leprosy. 